\title{
THE AETIOLOGY OF PULMONARY THROMBOSIS IN CYANOTIC CONGENITAL HEART DISEASE WITH PULMONARY STENOSIS
}

\author{
BY \\ DONALD HEATH,* JAMES W. DUSHANE, EARL H. WOOD, AND JESSE E. EDWARDS \\ From the Sections of Paediatrics, Physiology, and Pathologic Anatomy, Mayo Clinic and Mayo Foundation, \\ Rochester, Minnesota, U.S.A.
}

(RECEIVED FOR PUBLICATION MARCH 27, 1958)

Although a decade has passed since Rich (1948) reported the tendency of pulmonary thrombosis to develop in patients with Fallot's tetralogy, the aetiological factors concerned in this process have received little attention. He considered the classical pathological causes of thrombosis, namely anoxaemia, diminished pulmonary blood flow and increased blood viscosity, to be more important than pulmonary embolism, but he gave no physiological data to support this view. The purpose of this communication is to present the results of an investigation into the relationship between the incidence of pulmonary thrombosis and the age, pulmonary arterial blood pressure and flow, and the value for haemoglobin in 25 patients who had pulmonary stenosis and who died after cardiotomy. The operation had been preceded in most instances by physiological studies during cardiac catheterization utilizing techniques described previously (Barratt-Boyes and Wood, 1957). The present study is concerned with the cause of the thrombi and not with their characteristic form and distribution within the lung, which have been considered in seven different types of cyanotic congenital heart disease without pulmonary hypertension by Best and Heath (1958). In the course of the present investigation, we also recorded the incidence of medial hypertrophy in the muscular pulmonary arteries.

\section{Methods AND Material}

As already noted, a study was made of 25 patients who had pulmonary stenosis; this lesion was isolated in two cases, whereas it was associated with a ventricular septal defect in 15 cases, with an atrial septal defect in five, and with a common ventricle, corrected transposition of the vessels with atrial septal defect, and the

* Dr. Heath was in receipt of a Rockefeller travelling fellowship in medicine while participating in this investigation, which was supported in part by research grant No. H3531 from the National Heart Institute, National Institutes of Health, United States Public Health Service.
Taussig-Bing complex in single instances. These patients ranged in age from 2 to 44 years. The level of haemoglobin was known in each patient. The pulmonary arterial blood pressure had been measured during life in 19 instances, and data allowing calculation of the pulmonary blood flow had been collected in 13 . In order to reduce the effect of body size, the pulmonary blood flow is expressed as the "pulmonary index," which is the pulmonary blood flow in litres per minute per square metre of body surface. We regarded the resting normal pulmonary blood flow as lying in the range of 2.5 to 4.4 litres per minute per square metre of body surface (Barratt-Boyes and Wood, 1958). For the sake of brevity, the "pulmonary index" of flow hereinafter is referred to as a simple number.

Portions of lung obtained at necropsy were embedded in paraffin, and sections from these blocks were stained by haematoxylin and eosin and by Verhoeff's and van Gieson's methods. This material was examined histologically to determine the presence of thrombi in the small pulmonary vessels and to note any increase in thickness of the media of the small muscular pulmonary arteries. The normal medial thickness was taken to be $5 \%$ of the external diameter of the vessel (Heath and Best, 1958).

\section{RESULTS}

The age and sex of each of the patients, together with the physiological and pathological data, are shown in the accompanying table. The cases were divided into three groups.

Group 1.-In Cases 1 to 4, forming the first group, the media of the small muscular pulmonary arteries was abnormally thick (Fig. 1a). In each instance, this medial hypertrophy was associated with the presence of a distinct muscular media in the pulmonary arterioles (Fig. 1b). Cardiac catheterization had demonstrated mild or moderate pulmonary hypertension in three of the four patients in this group, the systolic blood pressure in the pulmonary artery exceeding $40 \mathrm{~mm}$. of mercury in each of them and reaching $63 \mathrm{~mm}$. in Case 4 . 
TABLE

DATA IN 25 PATIENTS WITH PULMONARY STENOSIS*

\begin{tabular}{|c|c|c|c|c|c|c|c|c|c|c|}
\hline \multirow{2}{*}{ Group } & \multirow{2}{*}{ Case } & \multirow{2}{*}{$\begin{array}{c}\text { Age } \\
\text { (Years) }\end{array}$} & \multirow{2}{*}{ Sex } & \multirow{2}{*}{$\begin{array}{l}\text { Associated } \\
\text { Defect } †\end{array}$} & \multicolumn{2}{|c|}{$\begin{array}{c}\text { Pulmonary Arterial } \\
\text { Pressure (mm. Hg) }\end{array}$} & \multirow{2}{*}{$\begin{array}{l}\text { Pulmonary } \\
\text { Blood Flow } \\
\left(1 . / \mathrm{min} . / \mathrm{m} .^{2}\right)\end{array}$} & \multirow{2}{*}{$\begin{array}{c}\text { Haemoglobin } \\
\text { (g. per } \\
100 \mathrm{ml} .)\end{array}$} & \multicolumn{2}{|c|}{ Occurrence of: } \\
\hline & & & & & Systolic & Diastolic & & & $\begin{array}{c}\text { Pulmonary } \\
\text { Thrombi }\end{array}$ & $\underset{\text { Hypertrophy }}{\text { Medial }}$ \\
\hline 1 & $\begin{array}{l}1 \\
2 \\
3 \\
4\end{array}$ & $\begin{array}{r}4 \\
4 \\
7 \\
22\end{array}$ & $\begin{array}{l}\mathbf{M} \\
\mathbf{M} \\
\mathbf{M} \\
\mathbf{F}\end{array}$ & $\begin{array}{l}\text { VSD } \\
\text { CV } \\
\text { VSD } \\
\text { VSD }\end{array}$ & $\begin{array}{l}44 \\
\frac{42}{63}\end{array}$ & $\begin{array}{r}33 \\
7 \\
34\end{array}$ & $\frac{11 \cdot 3}{8 \cdot 2}$ & $\begin{array}{l}13 \cdot 4 \\
18 \cdot 8 \\
13 \cdot 9 \\
12 \cdot 2\end{array}$ & $\begin{array}{l}\mathbf{0} \\
\mathbf{0} \\
\mathbf{0} \\
\mathbf{0}\end{array}$ & $\begin{array}{l}+ \\
+ \\
+ \\
+\end{array}$ \\
\hline 2 & $\begin{array}{r}5 \\
6 \\
7 \\
8 \\
9 \\
10\end{array}$ & $\begin{array}{l}3 \\
3 \\
4 \\
4 \\
5 \\
6\end{array}$ & $\begin{array}{l}\mathbf{M} \\
\mathbf{F} \\
\mathbf{M} \\
\mathbf{F} \\
\mathbf{F} \\
\mathbf{M}\end{array}$ & $\begin{array}{l}\text { ASD } \\
\text { T-B } \\
\text { VSD } \\
\text { O } \\
\text { VSD } \\
\text { VSD }\end{array}$ & $\begin{array}{l}\frac{16}{31} \\
\frac{22}{22}\end{array}$ & $\frac{\frac{11}{14}}{\frac{6}{13}}$ & $\begin{array}{l}\overline{-} \\
5 \cdot 3 \\
\overline{3 \cdot 6}\end{array}$ & $\begin{array}{l}16.4 \\
18.2 \\
12.9 \\
19.9 \\
12.7 \\
15.4\end{array}$ & $\begin{array}{l}\mathbf{0} \\
\mathbf{0} \\
\mathbf{0} \\
\mathbf{0} \\
\mathbf{0} \\
\mathbf{0}\end{array}$ & $\begin{array}{l}0 \\
0 \\
0 \\
0 \\
0 \\
0\end{array}$ \\
\hline 3 & $\begin{array}{l}11 \\
12 \\
13 \\
14 \\
15 \\
16 \\
17 \\
18 \\
19 \\
20 \\
21 \\
22 \\
23 \\
24 \\
25\end{array}$ & $\begin{array}{r}2 \\
3 \\
5 \\
7 \\
13 \\
13 \\
13 \\
17 \\
19 \\
20 \\
22 \\
23 \\
31 \\
43 \\
44\end{array}$ & $\begin{array}{l}\mathbf{F} \\
\mathbf{M} \\
\mathbf{F} \\
\mathbf{M} \\
\mathbf{M} \\
\mathbf{M} \\
\mathbf{M} \\
\mathbf{F} \\
\mathbf{F} \\
\mathbf{M} \\
\mathbf{M} \\
\mathbf{M} \\
\mathbf{M} \\
\mathbf{M} \\
\mathbf{F}\end{array}$ & $\begin{array}{l}\text { VSD } \\
\text { VSD } \\
\text { O } \\
\text { VSD } \\
\text { VSD } \\
\text { VSD } \\
\text { VSD } \\
\text { VSD } \\
\text { ASD } \\
\text { VSD } \\
\text { ASD } \\
\text { ASD } \\
\text { VSD } \\
\text { CT;ASD } \\
\text { ASD }\end{array}$ & $\begin{array}{l}16 \\
\overline{13} \\
18 \\
32 \\
18 \\
14 \\
25 \\
13 \\
34 \\
8 \\
35 \\
12\end{array}$ & $\begin{array}{r}4 \\
- \\
8 \\
7 \\
7 \\
10 \\
9 \\
20 \\
7 \\
27 \\
3 \\
15 \\
9\end{array}$ & $\begin{array}{l}\overline{2.2} \\
1.9 \\
1.8 \\
= \\
\overline{2.4} \\
4.7 \\
1.4 \\
\overline{-} \\
\overline{1.2} \\
1.6 \\
1.4\end{array}$ & $\begin{array}{l}13.9 \\
15 \cdot 4 \\
12.7 \\
18 \cdot 8 \\
12.7 \\
17 \cdot 1 \\
17.6 \\
14 \cdot 8 \\
17.6 \\
13 \cdot 7 \\
23 \cdot 2 \\
24 \cdot 0 \\
17.6 \\
22.0 \\
15.4\end{array}$ & $\begin{array}{l}+ \\
+ \\
+ \\
+ \\
+ \\
+ \\
+ \\
+ \\
+ \\
+ \\
+ \\
+ \\
+ \\
+ \\
+\end{array}$ & $\begin{array}{l}0 \\
0 \\
0 \\
0 \\
0 \\
0 \\
0 \\
0 \\
0 \\
0 \\
0 \\
0 \\
0 \\
0 \\
0\end{array}$ \\
\hline
\end{tabular}

* Arranged in order of increasing age for the three groups.

$+\mathrm{VSD}=$ ventricular septal defect; $\mathbf{A S D}=$ atrial septal defect; $\mathbf{C V}=$ common ventricle; $\mathbf{C T}=$ corrected transposition; $\mathrm{T}-\mathrm{B}=\mathrm{Taussig}-\mathrm{Bing}$ complex; $\mathrm{O}=$ isolated pulmonary stenosis.

None of the patients in this group had pulmonary thrombosis. Pulmonary blood flow was measured in Cases 1 and 4 and greatly exceeded the normal, the respective indices being 11.3 and 8.2. The haemoglobin levels in this group were not increased except in Case 2, in which the value was $18.8 \mathrm{~g}$. per $100 \mathrm{ml}$. of blood.

GROUP 2.-Neither pulmonary thrombosis nor medial hypertrophy of the small muscular pulmonary arteries was present in the second group, comprising Cases 5 to 10. The pressure in the pulmonary artery was normal or slightly reduced in these patients The pulmonary index was within normal limits in the two cases in which it had been calculated. The range of values for haemoglobin approximated that found in Group 1, being 12.7 to $19.9 \mathrm{~g}$. In Case 9 , although the pulmonary blood flow had not been calculated, it is assumed that it was not unduly

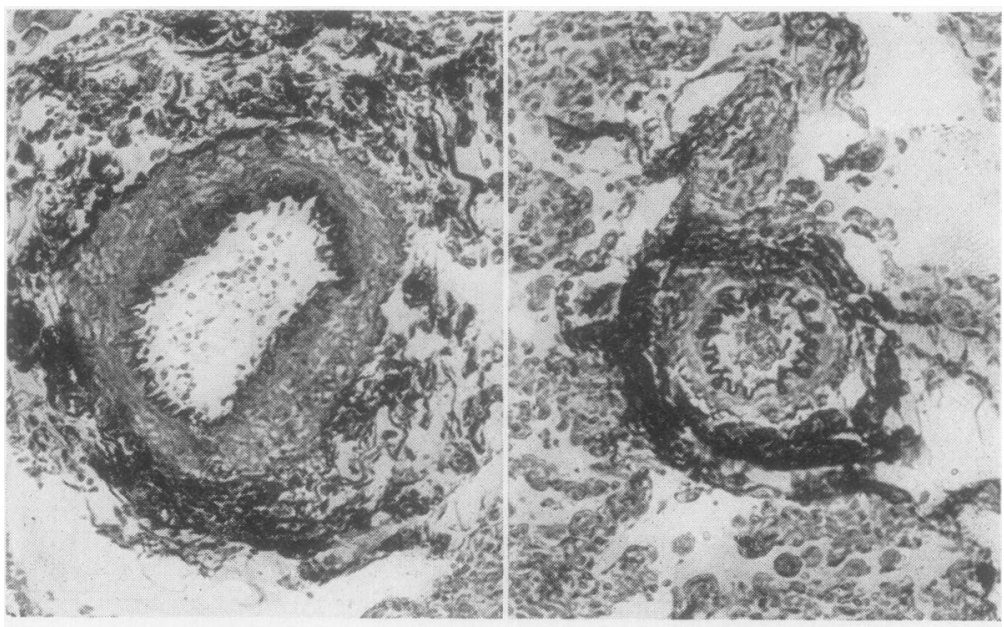

(a)
Fig. 1 (Case 4) -a. Muscular pulmonary artery, showing greatly thickened modia. Thrombosis is absent. This patient had " Fallot's tetralogy," with associated pulmonary hypertension (Verhooff-van Gioson; $\times$ 175). $b$. Pulmonary arteriole, showing greatly thickened modia. The wall of a normal pulmonary arteriole consists of a single olastic lamins beneath the endotholium (Verhoeff-van Gieson; $\times$ 200). 
(a)

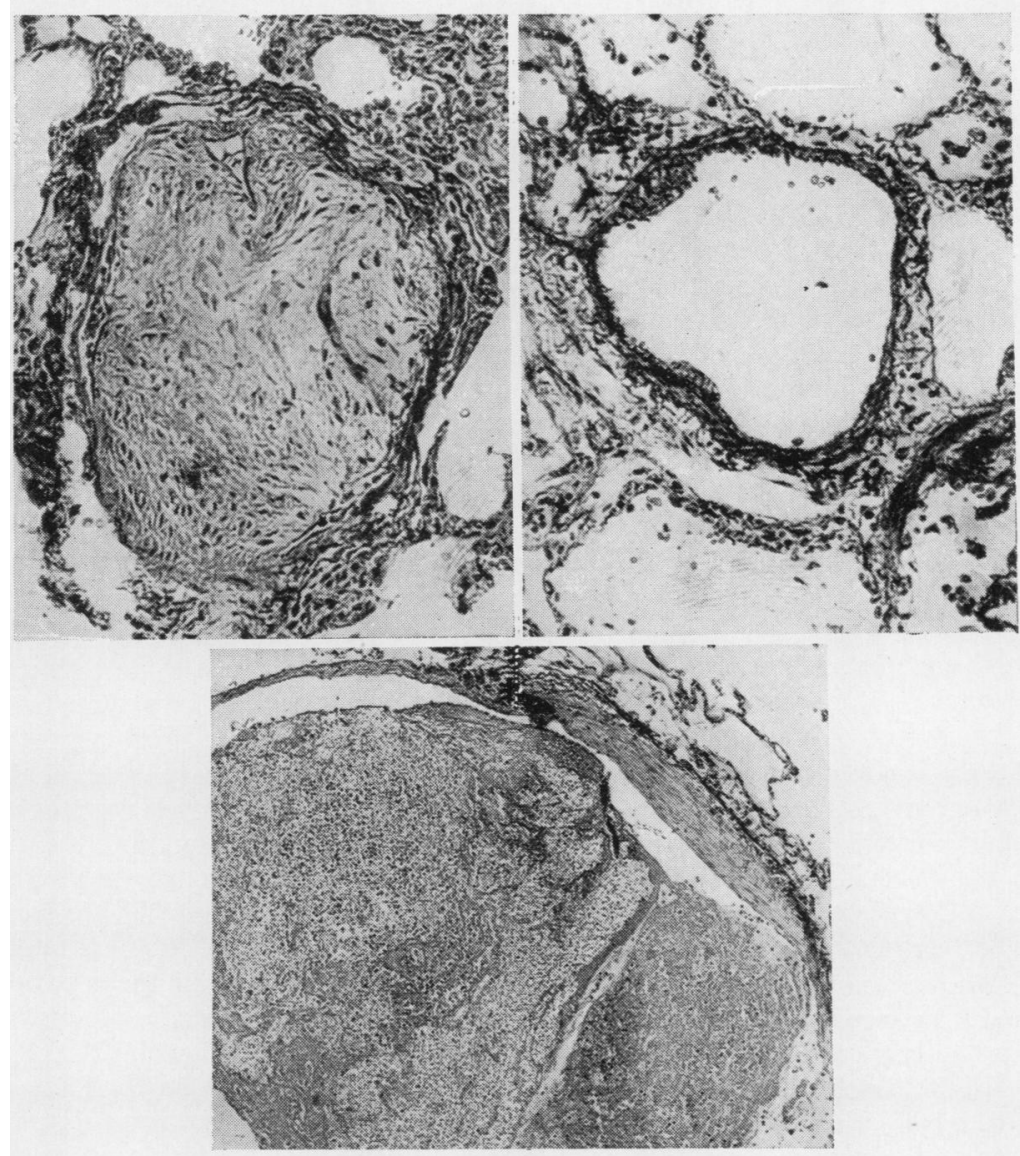

(c)
Fig. 2. $-a$. Muscular pulmonary artery (Caso 11). The media is extremely thin, and the vessel is totally occluded by organized thrombus. The pulmonary blood flow was not measured in this 2-year-old girl, who had a ventricular septal defect and severe pulmonary stenosis. Virtual pulmonary atrosia was reportod at cardiotomy (Verhoeff-van Gieson; $\times$ 175). b. Muscular pulmonary artery (Caso 18). The media is extromely thin. The vessol contains two small eccentric only ovidonce of pulmonary thrombosis in this 17-year-old girl who had a pulmonary index of 4.7, indicative of normal pulmonary blood flow (Verhoeffvan Gieson; $\times$ 175). $c$. Muscular pulmonary artery (Case 25). The modia is extremely thin, and the vessol contains both organized and recent thrombi. This 44-yearold woman had a pulmonary indox of 1.4 (haematoxylin and oosin; $\times$ 50). organized thrombi, which was the

(b)

diminished, as cardiotomy revealed the absence of valvular and infundibular stenosis and only a slight narrowing of the pulmonary trunk.

Group 3.-The third group included Cases 11 to 25 . It was characterized by pulmonary thrombosis without an increase in the thickness of the media of the muscular arteries (Fig. 2). The pulmonary arterial blood pressures were normal in some patients (Case 19), diminished in others (Case 22), and slightly increased in the remainder (Case 21). The pulmonary index was 1.9 or less in six of the nine cases in which it was determined; this value is well below the lower limit of normal. In two other instances, the indices were 2.2 and 2.4, figures that are still less than normal. In the ninth case, the index was normal (4.7), and only two isolated thrombi were found in this patient (Case 18 and Fig. 2b). Only four patients in the first decade of life fell into this third group; in the three of these patients in whom the pulmonary index had been calculated, the value was 2.2 or less. Although the pulmonary blood flow had not been measured in six patients with pulmonary thrombi, the surgeon had reported "virtual pulmonary atresia" or "severe pulmonary stenosis" in most of them at cardiotomy, suggesting that they had a low pulmonary index. In this third group, three patients had haemoglobin levels exceeding $20 \mathrm{~g}$.

\section{COMMENT}

These data indicate that pulmonary thrombosis is closely related to a decreased pulmonary blood flow. Thrombosis was always found when the pulmonary index was less than 2.5 , the lowest value in the range of normality. Although the total pulmonary blood flow is diminished in most cases of pulmonary stenosis associated with a ventricular 
septal defect, the flow in litres per minute per square metre of body surface frequently exceeded 2.5 in the first decade of life in the cases studied, such as Cases 7 and 10. This means that pulmonary thrombosis was found in this age group only in extremely severe pulmonary stenosis, such as in Cases 13 and 14, in which the pulmonary indices were only 1.9 and 1.8 , respectively.

As the patient who has pulmonary stenosis grows older, the size of the congenitally abnormal pulmonary valve tends to remain fixed, and progressive fibrosis of the infundibulum may diminish the size of the right ventricular outflow tract while the patient's height and weight are increasing. This lack of growth of the pulmonary tract commensurate with that of the body as a whole leads to progressive diminution of the pulmonary index. In our older patients of this group, the index was less than 2 (Cases 19, 22, 24, and 25). Hence, it was found that pulmonary thrombosis was almost universal in the second decade of life and beyond in this group of patients with cyanotic congenital heart disease and pulmonary stenosis.

In exceptional cases, the pulmonary index may remain normal in adult life, as in Case 18, in which the patient had a pulmonary index of 4.7 at the age of 17 years; under such circumstances, pulmonary thrombi are virtually absent.

With increasing age and a diminishing pulmonary blood flow, progressive anoxaemia occurs, and this leads to compensatory polycythaemia, which increases the blood viscosity. This is an added factor in the production of pulmonary thrombi and may assume importance if the value for haemoglobin exceeds $20 \mathrm{~g}$., as in Cases 21 and 22.

Age itself is a third factor predisposing to thrombosis, for it determines the duration of the preceding factors of diminished pulmonary blood flow and of increased blood viscosity, which obviousiy are of importance.

When mild or moderate pulmonary stenosis is associated with a large ventricular septal defect, a high pulmonary blood flow may be present (Broadbent, Wood, and Burchell, 1953), as in Cases 1 and 4, and such acyanotic patients will have neither of the two main factors predisposing to pulmonary thrombi. Furthermore, it is not generally appreciated in the group of patients in whom pulmonary stenosis is associated with a large ventricular septal defect that the stenosis may not be severe enough to attenuate the propagated systolic pulse of the ventricles into the pulmonary circulation (Broadbent and others, 1953; Edwards, 1957). Hence, the small pulmonary blood vessels remain thickwalled from birth in such patients to give rise to an early stage of hypertensive pulmonary vascular disease, as in Group 1. This indicates clearly that, while the classical term "tetralogy of Fallot" denotes a precise anatomical entity, it has no specific functional connotation and leads to confusion in that pulmonary thrombosis on one hand and medial hypertrophy of small muscular pulmonary arteries on the other occur in different groups of patients said to be suffering from the same anatomical type of malformation. The use of alternative nomenclature, namely, "a large ventricular septal defect with severe pulmonary stenosis" and "a large ventricular septal defect with mild pulmonary stenosis," would provide a clearer concept of the physiological conditions in the pulmonary circulation, with their associated pathological and clinical significance.

Since all three different functional groups have been included, that is, patients in the first decade of life with an adequate pulmonary index and those acyanotic patients with a high pulmonary blood flow, as well as the classical patient with a low pulmonary index and a high haemoglobin level in the second decade of life and beyond, it is not surprising that the occurrence of thrombi in this series is less than that in the patients reported by Rich (1948). He found pulmonary thrombosis i $90 \%$ of his 21 patients who had Fallot's tetraloge and 16 of these patients with thrombi were in the first decade of life. Pulmonary thrombosis was found in $60 \%$ of the present series of patients and in only $30 \%$ of those less than 10 years of age. This apparent discrepancy would be expected if all of Rich's patients were cyanotic and had low pulmonary blood flow. It is, in fact, highly likely that most of Rich's patients were of this type, for, at the time of his report from the Johns Hopkins Hospital, such patients were being sent there from a large area to benefit from the Blalock-Taussig anastomotic operation pioneered at that centre (Blalock, 1948).

\section{SUMMARY}

The relationship of the incidence of pulmonary thrombosis to age, pulmonary arterial blood flow, and haemoglobin level was investigated in 25 patients with pulmonary stenosis, which was associated with a septal defect in all but two patients.

Pulmonary thrombosis was present when the pulmonary index was less than 2.5 litres per minute per square metre of body surface but was absent when the flow index was normal or increased. In the presence of a ventricular septal defect when the pulmonary blood flow was abnormally high, pulmonary hypertension and the early structural 
changes of hypertensive pulmonary vascular disease in the form of medial hypertrophy in the muscular pulmonary arteries and arterioles were present.

The second factor predisposing to pulmonary thrombosis in patients with low pulmonary blood flows was the increase of blood viscosity due to the compensatory polycythaemia stimulated by the anoxaemia found in such patients.

An indirect relationship exists between pulmonary thrombosis and age, since the pulmonary index tends to decrease with increasing age in patients with pulmonary stenosis, and the factors predisposing to thrombosis have existed for corresponding periods of time and possibly with increased severity. Widespread thrombosis was found in all but two of these patients more than 10 years of age; one of these exceptions had a high pulmonary blood flow and hypeitensive pulmonary vascular disease and the other had a normal blood flow and only two isolated thrombi. Conversely, only four of the 10 patients less than 10 years of age without pulmonary hypertension had pulmonary thrombi; in three of these, the pulmonary flow index was 2.2 or less.

The "tetralogy of Fallot," while denoting a precise anatomical entity, has no specific functional significance, and an alternative nomenclature is supported.

\section{REFERENCES}

Barratt-Boyes, B. G., and Wood, E. H. (1957). J. Lab. clin. Med., 50, 93.

- (1958). Ibid., 51, 72.

Best, P. V, and Heath, D. (1958), J Path. Bact, 75, 281.

Blalock, A. (1948). Surg. Gynec. Obstet., 87, 385 .

Broadbent, J. C., Wood, E. H., and Burchell, H. B. (1953). Pros. Mayo Clin.,28, 101

Edwards, J. E. (1957). Circulation, 15, 164

Heath, D., and Best, P. V. (1958). J. Path. Bact., 76, 165.

Rich, A. R. (1948). Bull. Johns Hopk. Hosp., 82, 389. 